\title{
Case Report \\ Glomus Tumor of the Cheek: A Case Report
}

\author{
Konstantinos Veros, ${ }^{1}$ Konstantinos Markou, ${ }^{1}$ Chrysa Filitatzi, ${ }^{2}$ and Dionysios E. Kyrmizakis ${ }^{3}$ \\ ${ }^{1}$ 1st Department of Otorhinolaryngology Head \& Neck Surgery, AHEPA University Hospital, 54006 Thessaloniki, Greece \\ ${ }^{2}$ Department of Pathology, General Hospital of Veroia, 59100 Veroia, Greece \\ ${ }^{3}$ Department of Otorhinolaryngology Head \& Neck Surgery, General Hospital of Veroia, 59100 Veroia, Greece
}

Correspondence should be addressed to Konstantinos Markou, kmarkou@med.auth.gr

Received 12 April 2012; Accepted 10 June 2012

Academic Editor: M. Mack

Copyright (๑) 2012 Konstantinos Veros et al. This is an open access article distributed under the Creative Commons Attribution License, which permits unrestricted use, distribution, and reproduction in any medium, provided the original work is properly cited.

Glomus tumors are benign, subcutaneous neoplasms of the perivasculature. Though facial location is rare, the diagnosis of a glomus tumor should be considered in cases of undiagnosed painful facial nodules or chronic facial pain. Imaging aids in defining the tumor and planning a complete excision in order to avoid recurrence. Histological examination is mandatory after every attempted excision. A case of glomus tumor of the cheek along with the possible pitfalls of diagnosis and treatment and a brief review of the limited associated literature are presented.

\section{Introduction}

Glomus tumors are benign neoplasms of the perivasculature accounting for $1-2 \%$ of soft tissue tumors [1]. They usually present as painful subcutaneous nodules commonly described in the subungual area of the digits. Though various other locations have been described, glomus tumors of the cheek are rare. In a reported study of 56 extradigital glomus tumors seen in Mayo Clinic over a period of twenty years (1985-2005), the authors found a single case occurring in the cheek [2]. Apart from the classic triad of symptoms described for glomus tumors, pain, localised tenderness, and cold hypersensitivity, the rare occurrence of glomus tumor in the cheek can be the cause of undiagnosed chronic facial pain. We present a case of a glomus tumor of the cheek mentioning the issues we encountered and briefly review the limited available literature for this rare entity.

\section{Case Report}

A 24-year-old man presented at our clinic with a fouryear history of a painful nodule in his left cheek that reoccurred after two attempted excisions in the last four months by different specialists. No biopsy result or other histological information was available. Otherwise healthy, the patient complained of pain and local tenderness. Clinical examination revealed a well-defined, round, firm nodule in the middle of the left cheek, approximately $1 \times 1 \mathrm{~cm}$ in size that appeared to be subdermic with no apparent fixation to the underlying tissues. The overlying skin was normal and the nodule was extremely painful on palpation. Examination of the oral cavity was normal and no neck lymph nodes could be palpated. Complete head and neck examination and laboratory tests were also unremarkable. Contrast enhanced CT (puffed cheek method) revealed a well-defined, contrastenhanced, round soft-tissue mass of the left cheek over the buccinator muscle measuring $13.8 \times 9 \mathrm{~mm}$, with no apparent relations to the surrounding tissues (Figure 1). Attached to it a very small satellite lesion was noted. In the operating room under local anesthesia, a relatively wide excision in order to remove both the masses was performed. Though we were not able to demarcate the main and satellite nodules macroscopically, no evidence of residual disease was apparent. Special care was taken regarding the protection of facial nerve branches and the cosmetic result. Histological examination of the specimen was consistent with the diagnosis of glomus tumor of the solid type, with no mention of potential residual disease (Figure 2). The patient reported relief of his symptoms after surgery, but at 2-month followup he complained of gradual recurrence of local 


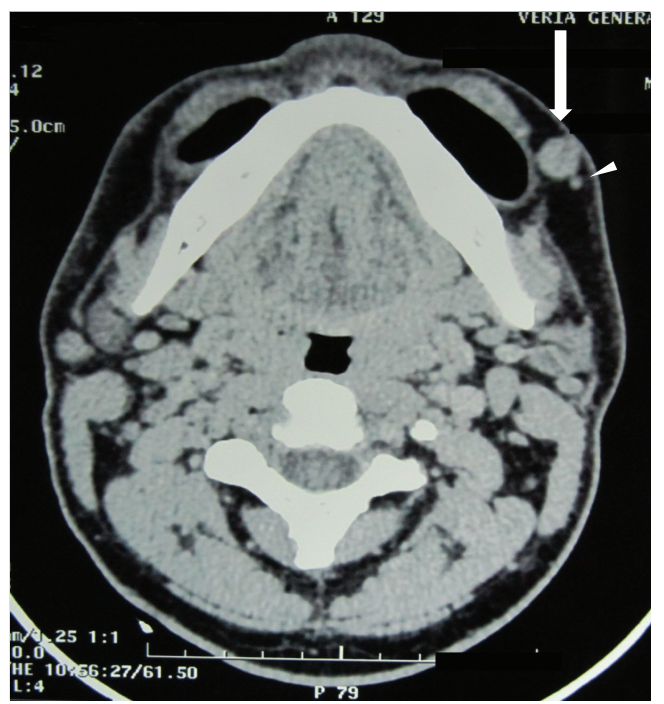

FIGURE 1: Contrast-enhanced CT (puffed cheek method) revealed a well-defined, enhanced, round soft-tissue mass of the left cheek over the buccinator muscle (arrow) measuring $13.8 \times 9 \mathrm{~mm}$ along with a tiny satellite lesion (arrowhead).

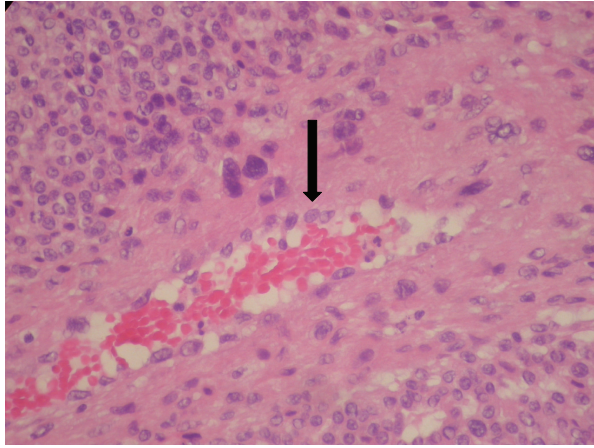

Figure 2: Hematoxylin and eosin stain, $\times 40$. Glomus tumor of the solid type. Infiltration of the vessel wall by the neoplastic cells (arrow) does not indicate malignancy.

tenderness at the site of the excision. Three months later, the patient had a small palpable nodule and complete recurrence of his symptoms. Under local anesthesia, a very wide excision including the previous scar (with approximately $1 \mathrm{~cm}$ margin around the scar) was performed. Histological examination revealed glomus tumor with solid, angiomatoid, and angiomyomatous features (Figure 3 ). The margins of the excision were reported as free of lesion. The patient remains without any symptoms nine months after surgery.

\section{Discussion}

Glomus tumors are neoplasms of the glomus body, a neuromyoarterial unit found within the reticular dermis that serves as a specialized arteriovenous anastomosis [3]. The arterial end of the glomus body or Sucquet-Hoyer canal is surrounded by modified smooth muscle cells called glomus cells that act to regulate blood flow to the skin in response to temperature changes [3-5]. The normal glomus body was

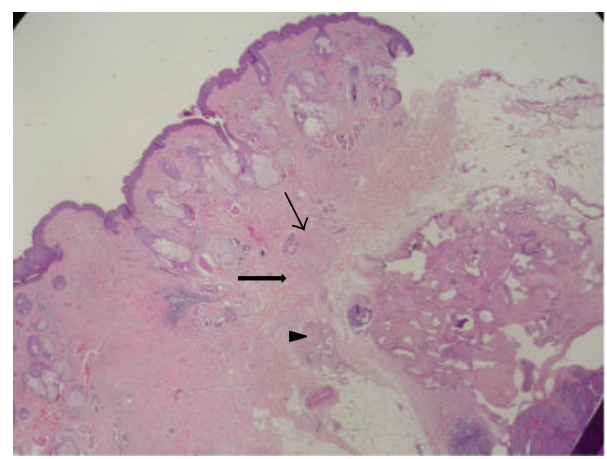

Figure 3: Hematoxylin and eosin stain, $\times 10$. Glomus tumor with solid (thin arrow), angiomatoid (arrowhead), and angiomyomatous (arrow) features.

first described by Hoyer in 1877, whereas Masson [6] in 1924 provided the first clinical description of a glomus tumor. Histologically, depending on the predominant component, there are three variants of glomus tumor, namely: (1) solid, with poor vasculature and scant smooth muscle component; (2) angiomatoid (glomangioma), with a predominant vascular component; (3) glomangiomyoma, with prominent vascular and smooth muscle components [7].

Accounting for 1-2\% of soft tissue tumors [1], glomus tumors present mostly as solitary masses with a rarer multiple variant $[8,9]$. Malignant transformation is extremely rare. Glomus bodies are most highly concentrated in the digits, palms, and soles of the feet [4], and glomus tumors are most commonly described in the upper extremity and especially in the subungual area of the digits. While extradigital glomus tumors are not a rare subgroup of glomus tumors [2] and various locations have been described, facial location and especially in the cheek is rare and only a few cases have been reported in the literature [2,10-12]. 
The symptoms and signs of a facial glomus tumor may vary from an asymptomatic (rarely) subcutaneous nodule to excruciating chronic facial pain. The most expected presentation is that of a small, painful, subcutaneous nodule. A long history of consultations by various specialists without a definite diagnosis can be expected. The classic triad of symptoms described for glomus tumors consisting of pain, localised tenderness, and cold hypersensitivity may or may not be present. Overlying skin may or may not be discoloured. Though usually not larger than $1 \times 1 \mathrm{~cm}$ in size, large facial glomangiomas mimicking venous malformations have been reported [10]. A 4:1 male predominance has been reported for extradigital glomus tumors [2].

Magnetic resonance imaging has proven to be the most sensitive imaging modality for the diagnosis of glomus tumors in the extremities [13-15]. Contrast enhanced CT can aid in the differential diagnosis and in delineating the anatomic relations necessary for operative management. Because of their small size and subcutaneous location, glomus tumors are particularly amenable to complete removal thus making surgical excision the treatment of choice. Histological examination is necessary to confirm the diagnosis, and documentation should be provided to the patient. Though excellent results can be anticipated, recurrence rates vary from $12 \%$ to $33 \%$ [16-19]. As in our case, it is not clear whether recurrence represents inadequate excision or the presence of multiple tumors not detected at initial assessment of the patient. Recurrence within days to weeks of surgery may suggest inadequate excision [18]; in contrast, symptoms 2 to 3 years postoperatively may indicate multiple tumors $[13,17]$. On account of the limited associated literature, further data regarding specifically facial glomus tumors are needed.

\section{References}

[1] S. W. Enzinger and F. M. Weiss, Soft Tissue Tumors, Mosby, St. Louis, Mo, USA, 3rd edition, 1995.

[2] T. K. Schiefer, W. L. Parker, O. A. Anakwenze, P. C. Amadio, C. Y. Inwards, and R. J. Spinner, "Extradigital glomus tumors: a 20-year experience," Mayo Clinic Proceedings, vol. 81, no. 10, pp. 1337-1344, 2006.

[3] C. Fletcher, "Tumours of blood vessels and lymphatics," in Diagnostic Histopathology of Tumors, pp. 75-76, Churchill Livingstone, Edinburgh, UK, 2000.

[4] T. B. Fitzpatrick, R. A. Johnson, K. Wolf, M. K. Polano, and D. Suurmond, Color Atlas and Synopsis of Clinical Dermatology, McGraw-Hill, 3rd edition, 1997.

[5] M. A. Venkatachalam and J. G. Greally, "Fine structure of glomus tumor: similarity of glomus cells to smooth muscle," Cancer, vol. 23, no. 5, pp. 1176-1184, 1969.

[6] P. Masson, "Le glomus neuromyoarterial des regions tactiles et ses tumeurs," Lyon Chir, vol. 21, pp. 257-280, 1924.

[7] Z. Gombos and P. J. Zhang, "Glomus tumor," Archives of Pathology and Laboratory Medicine, vol. 132, no. 9, pp. 1448-1452, 2008.

[8] J. S. Chatterjee, A. H. K. Youssef, R. M. Brown, and H. Nishikawa, "Congenital nodular multiple glomangioma: a case report," Journal of Clinical Pathology, vol. 58, no. 1, pp. 102$103,2005$.
[9] V. O. Carvalho, K. Taniguchi, S. Giraldi et al., "Congenital plaquelike glomus tumor in a child," Pediatric Dermatology, vol. 18, no. 3, pp. 223-226, 2001.

[10] C. Mounayer, M. Wassef, O. Enjolras, M. Boukobza, and J. B. Mulliken, "Facial "glomangiomas": large facial venous malformations with glomus cells," Journal of the American Academy of Dermatology, vol. 45, no. 2, pp. 239-245, 2001.

[11] T. H. Yang, Y. S. Kim, M. K. Kim, and T. Y. Yoon, "Glomangiomyoma on the face," Annals of Dermatology, vol. 14, no. 1, pp. 31-34, 2002.

[12] B. Wang, J. Wang, J. Shehan, and D. P. Sarma, "Glomus tumor of the cheek," The Internet Journal of Dermatology, vol. 6, no. 2, 2008.

[13] M. Holzberg, "Glomus tumor of the nail: a "red herring" clarified by magnetic resonance imaging," Archives of Dermatology, vol. 128, no. 2, pp. 160-162, 1992.

[14] J. L. Drapé, I. Idy-Peretti, S. Goettmann, H. Guérin-Surville, and J. Bittoun, "Standard and high resolution magnetic resonance imaging of glomus tumors of toes and fingertips," Journal of the American Academy of Dermatology, vol. 35, no. 4, pp. 550-555, 1996.

[15] M. M. Al-Qattan, A. Al-Namla, A. Al-Thunayan, F. Al-Subhi, and A. F. El-Shayeb, "Magnetic resonance imaging in the diagnosis of glomus tumours of the hand," Journal of Hand Surgery, vol. 30, no. 5, pp. 535-540, 2005.

[16] R. E. Carroll and A. T. Berman, "Glomus tumors of the hand: review of the literature and report on twenty-eight cases," Journal of Bone and Joint Surgery A, vol. 54, no. 4, pp. 691-703, 1972.

[17] J. P. W. Varian and D. K. Cleak, "Glomus tumours in the hand," Hand, vol. 12, no. 3, pp. 293-299, 1980.

[18] A. C. Rettig and J. W. Strickland, "Glomus tumor of the digits," Journal of Hand Surgery, vol. 2, no. 4, pp. 261-265, 1977.

[19] J. Strahan and H. W. Bailie, "Glomus tumour: a review of 15 clinical cases," British Journal of Surgery, vol. 59, no. 2, pp. 9193, 1972. 


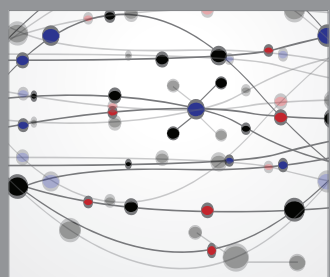

The Scientific World Journal
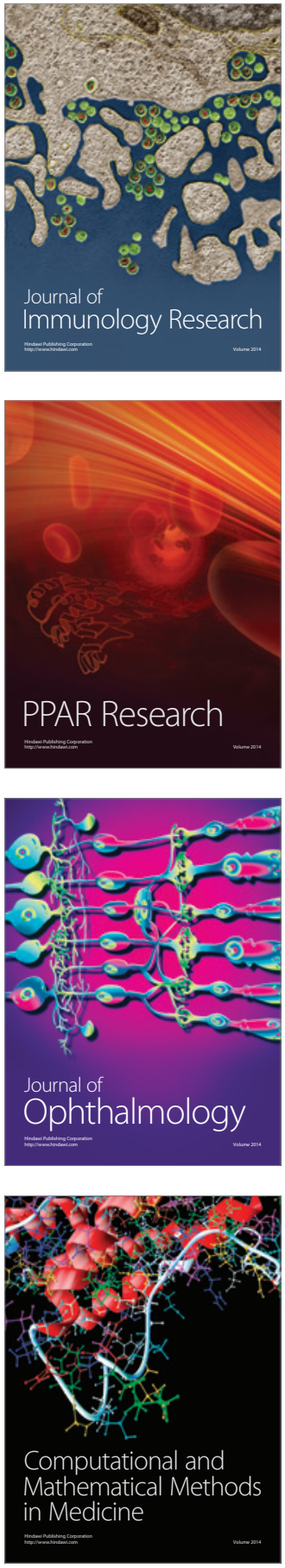

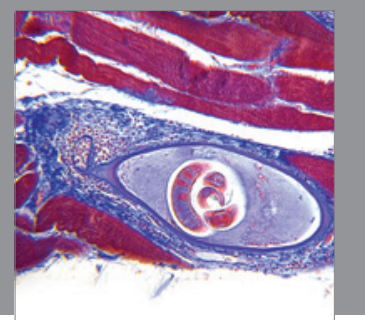

Gastroenterology

Research and Practice
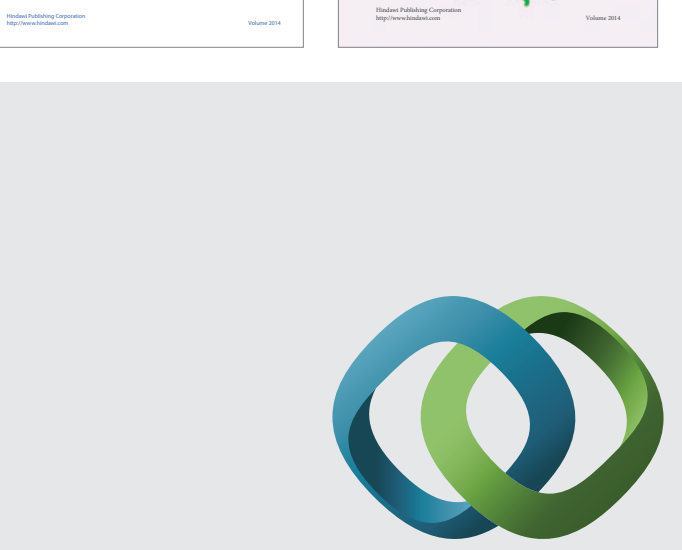

\section{Hindawi}

Submit your manuscripts at

http://www.hindawi.com
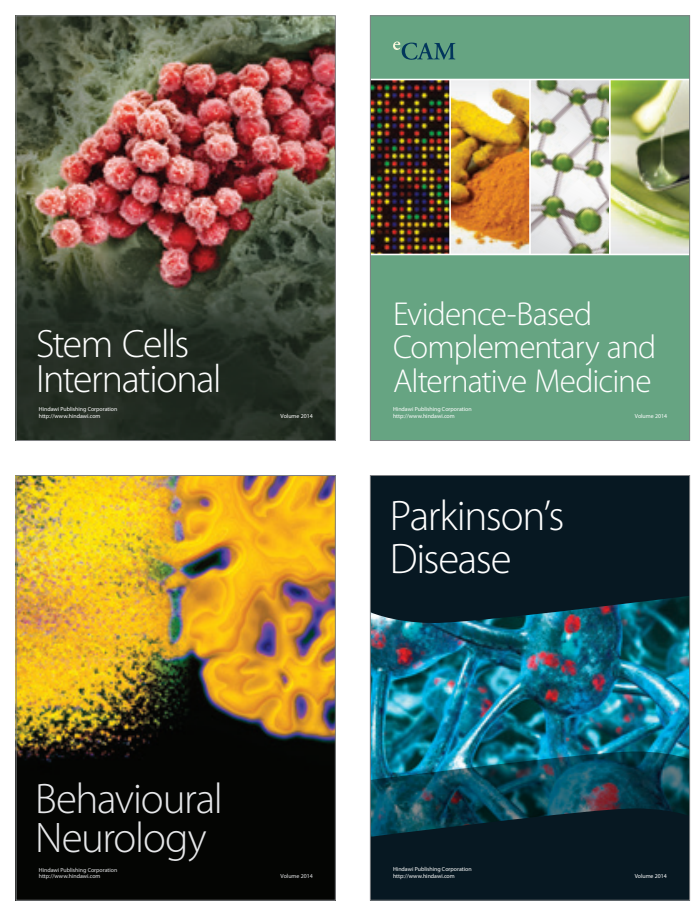

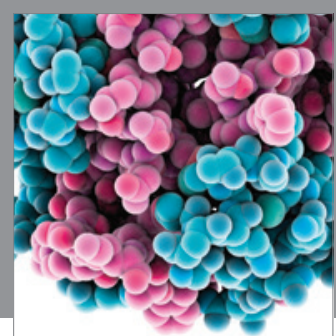

Journal of
Diabetes Research

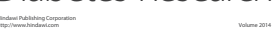

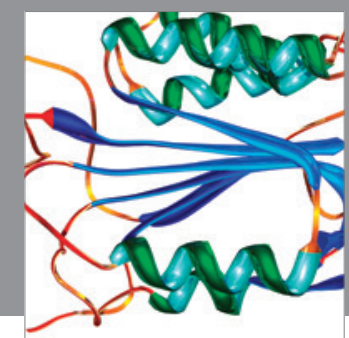

Disease Markers
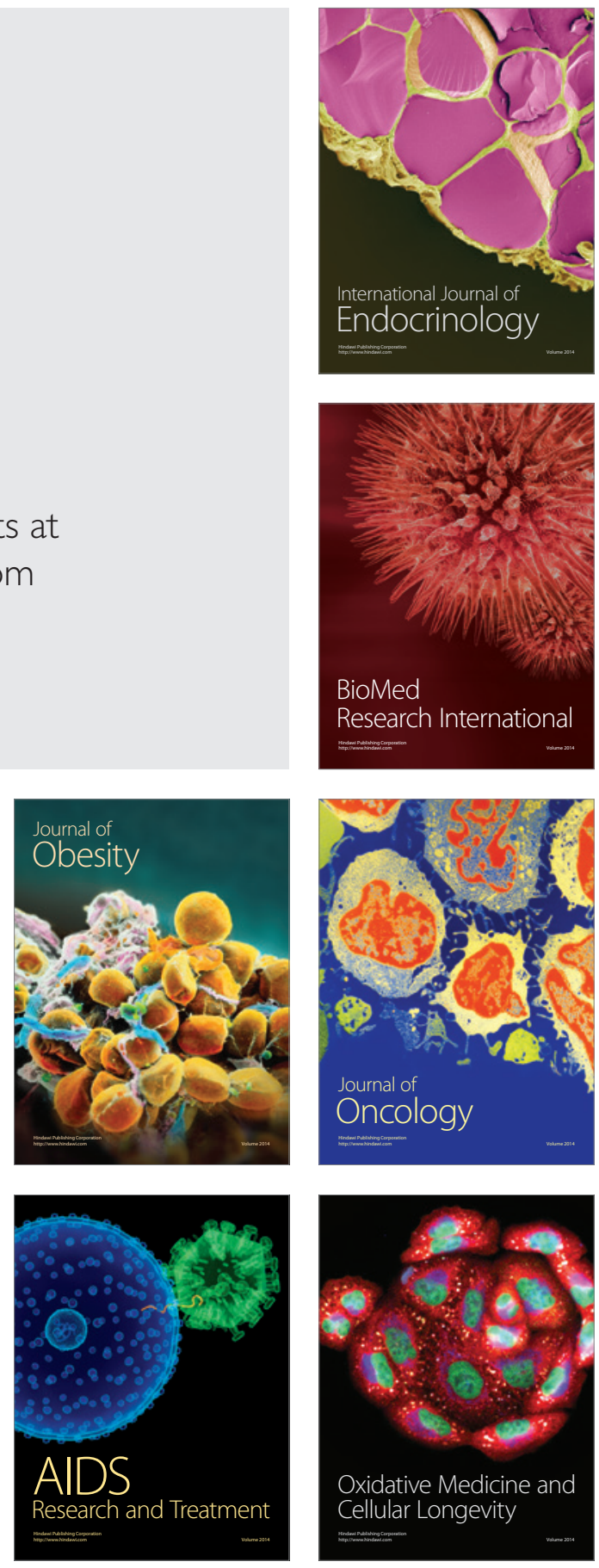